ESPAÇO TEMÁTICO: TRABALHO, TECNOLOGIAS DA INFORMAÇÃO E COMUNICAÇÃO E

CONDIÇÕES DE VIDA

\title{
Marx e a indústria 4.0: trabalho, tecnologia e valor na era digital
}

\author{
Wecio Pinheiro Araujo ${ }^{1}$ \\ https://orcid.org/0000-0003-2874-3052 \\ ${ }^{1}$ Universidade Federal da Paraíba, Departamento de Serviço Social, Programa de pós-graduação em Serviço Social, João \\ Pessoa, PB, Brasil
}

\section{Marx e a indústria 4.0: Trabalho, tecnologia e valor na era digital}

Resumo: Este artigo problematiza alguns aspectos da automação e da digitalização para a produção capitalista a partir da chegada da Indústria 4.0, com ênfase na questão da acumulação de capital na forma de valor (Wertform). Estes fenômenos são abordados sob a perspectiva marxiana do trabalho produtivo, com foco na relação entre trabalho, tecnologia e valor, sob a inflexão das contradições estabelecidas entre trabalho vivo e trabalho morto na era digital deste século XXI. A questão nevrálgica está em como o trabalho morto "ganha vida" com a ascensão dos robôs dotados de inteligência artificial, e como uma força autônoma subjuga o trabalho vivo ao mesmo tempo que produz o seu progressivo descarte na forma de complexas contradições imanentes à produção automatizada/digitalizada. A metodologia utilizada foi a pesquisa bibliográfica, no tocante ao debate teórico historicamente acumulado, e também a pesquisa documental para levantamento de dados em fontes secundárias. Palavras-chave: Marx; Indústria 4.0; Trabalho; Tecnologia; Valor.

\section{Marx and industry 4.0: labor, technology and value in the digital age}

Abstract: This article discusses some aspects of automation and digitization for capitalist production since the arrival of Industry 4.0, with an emphasis on the issue of capital accumulation in the form of value (Wertform). These phenomena are approached from the Marxian perspective of productive labor, focusing on the relationship between labor, technology and value, under the inflection of the contradictions established between live labor and labor work in the digital age of this $21 \mathrm{st}$ century. The neuralgic issue is how dead labor "gains life" with the rise of robots endowed with artificial intelligence, and how an autonomous force subjugates live labor while producing its progressive disposal in the form of complex contradictions immanent to automated production/scanned. The methodology used was bibliographical research, regarding the historically accumulated theoretical debate, and also documental research for data collection from secondary sources.

Keywords: Marx; Industry 4.0; Labor; Technology; Value.

Recebido em: 01.07.2021. Aprovado em: 31.08.2021. Revisado em: 17.09.2021. 
Introdução

O capital é trabalho morto, que, como um vampiro, vive apenas da sucção de trabalho vivo, e vive tanto mais quanto mais trabalho vivo suga. (MARX, 2013, p. 307)

Quando um sistema automatizado assume o lugar de uma operação humana, o processo de produção de valor passa a ter mais capital (trabalho morto) e menos mão de obra (trabalho vivo). O objetivo desta exposição é examinar esta questão sob a perspectiva marxiana do trabalho produtivo e sua relação com o desenvolvimento tecnológico na chamada Indústria $4.0^{1}$. Todavia, não se trata de abordar a problemática apenas sob o viés da substituição do trabalho vivo pelo trabalho morto, mas também, e sobretudo, como um despertar digital automatizado do trabalho morto, que como uma força autônoma assume cada vez mais o controle sobre o trabalho vivo, de modo que, no processo de produção global, consolida e aprofunda a subsunção do trabalho ao capital sob o desenvolvimento de fatores tecnológicos neste século XXI. Para examinar a problemática em tela, realizamos um estudo sincrônico estabelecido entre, de um lado, os Grundrisse (MARX, 2011) e um extrato dos manuscritos correspondentes a um período posterior a estes (1861-63), intitulado Maquinaria e trabalho vivo (MARX, 1994), e de outro, alguns capítulos do livro primeiro d' O Capital $(2013 ; 2016)^{3}$.

A questão nevrálgica que temos a examinar está situada em como, na Indústria 4.0, o trabalho morto "ganha vida" por meio das máquinas automatizadas, de modo que como uma força autônoma subjuga o trabalho vivo, levando assim à sua progressiva substituição, porém, isto de modo algum significa a completa eliminação do trabalho vivo em termos do processo de produção global, isto é, tomado em seu conjunto. Afinal, se por um lado, o trabalho vivo é imprescindível para a própria produção de máquinas, por outro, o desenvolvimento tecnológico, ao mesmo tempo que reduz o quantum de trabalho vivo, também cria novos postos de trabalho a partir do surgimento de novas especializações na divisão do trabalho ${ }^{4}$. Não obstante, no saldo final, em termos da produção global, o trabalho vivo sofre progressiva redução, tendo em vista que, quantitativamente, o surgimento das novas especializações não é suficiente para compensar o seu descarte. Vejamos como Marx analisa inicialmente a questão.

Portanto, a fórmula da maquinaria é: não a diminuição relativa da jornada individual de trabalho - jornada esta que é parte necessária da jornada de trabalho -, mas a redução da quantidade de trabalhadores, isto é, das muitas jornadas paralelas, formadoras de uma jornada coletiva de trabalho, fundamental à constituição da maquinaria. Em outros termos, uma quantidade determinada de trabalhadores é posta para fora do processo de produção e seus postos de trabalho extintos como sendo, ambos, inúteis à produção de mais-trabalho. Tudo isso abstraindo da eliminação daquelas especializações surgidas mediante a divisão do trabalho de onde resulta, por consequência, uma depreciação da própria capacidade de trabalho. $\mathrm{O}$ trabalho passado juntamente com a circulação social do trabalho, são apreendidos como meios de tornar supérfluo o trabalho vivo (MARX, 1994, p. 106).

Inicialmente, enquanto trabalho morto - neste caso específico supracitado, denominado por Marx como trabalho passado ${ }^{5}$, a máquina se torna o principal conduto de passagem para a redução do trabalho vivo no processo global de produção sob o fator tecnológico. Esta mediação nos coloca diante de complexas contradições - conforme aprofundaremos ao longo desta exposição. Para iniciar a sua elucidação, Marx nos fornece uma chave de leitura que tem seu ponto de partida no fato de que, sob o desenvolvimento tecnológico (que ele chama de maquinaria), a hostilidade entre capital e trabalho progride como uma contradição que se realiza por meio de um movimento sincrônico de atração e repulsão.

Esta é a tendência da maquinaria: por um lado, a constante expulsão de trabalhadores, seja do interior daquela oficina já mecanizada, seja do interior dos ofícios; por outro, sua constante reintegração, posto que a partir de um grau determinado de desenvolvimento da força produtiva, o aumento da mais-valia só se coloca com a elevação simultânea do número de trabalhadores ocupados. Esse movimento de atração e expulsão é característico e representa o constante oscilar da existência do trabalhador (MARX, 1994, p. 107).

Neste contexto, conforme segue a análise, Marx conclui que 
A oposição entre capital e trabalho assalariado desenvolve-se, assim, até sua plena contradição. É no interior desta que o capital aparece como meio não somente de depreciação da capacidade viva de trabalho, mas também como meio de torná-la supérflua. Em determinados processos isso ocorre por completo; em outros, esta redução se efetua até que se alcance o menor número possível no interior do conjunto da produção (MARX, 1994, p. 106).

Na Indústria 4.0, com a automação digital, a oposição entre capital e trabalho produz ainda mais reificação para as relações de produção, ao passo que estas se tornam relações entre coisas que adquirem vida própria na forma do robô dotado de inteligência artificial. Neste contexto, a questão fundamental a ser examinada inclui um aspecto que se torna determinante na era digital: o momento que o trabalho morto não somente substitui, mas, sobretudo, age como uma força autônoma sobre o trabalho vivo. Nesta direção, de maneira mais específica ao campo da tecnologia, faz-se imprescindível primeiramente explanar algumas questões e conceitos fundamentais para que possamos contextualizar melhor aquilo que compreendemos como automação e digitalização da produção sob a gestão dos algoritmos.

\section{Automação e produção capitalista: trabalho, algoritmos e digitalização}

Na sociedade capitalista contemporânea, a arquitetura indivíduo-máquina, na interface do processo produtivo, vem evoluindo na forma de complexos sistemas digitais de controle amplo e distribuído do trabalho socialmente combinado. Deste modo, processos analógicos e digitais são executados sob a gestão algorítmica, consolidando e aprofundando as consequências sociais decorrentes do desenvolvimento tecnológico das forças produtivas. No contexto da Indústria 4.0, chegamos ao momento no qual o trabalho morto vem se tornando cada vez mais autônomo perante o trabalho vivo, à medida que as máquinas começam a aprender e interagir entre si de maneira automatizada, por meio da inteligência artificial e da internet das coisas (da sigla em inglês IoT: internet of things) - o que explicaremos mais à frente. Este processo faz surgir a interface máquina-máquina que, em alguns casos, já é capaz de dispensar quase que completamente a atuação humana direta. Segundo Schwab (2016, p. 26-27),

Uma das principais pontes entre as aplicações físicas e digitais, originadas pela quarta revolução industrial, é a internet das coisas (IoT) - às vezes chamada de "a internet de todas as coisas". Em sua forma mais simples, ela pode ser descrita como a relação entre as coisas (produtos, serviços, lugares etc.) e as pessoas que se torna possível por meio de diversas plataformas e tecnologias conectadas. Os sensores e vários outros meios de conectar as coisas do mundo físico às redes virtuais estão se proliferando em um ritmo impressionante. Sensores menores, mais baratos e inteligentes estão sendo instalados em casas, roupas e acessórios, cidades, redes de transportes e energia, bem como nos processos de fabricação. Hoje, existem bilhões de dispositivos em todo o mundo, como smartphones, tablets e computadores conectados à internet. Espera-se que o número desses dispositivos aumente dramaticamente nos próximos anos; as estimativas variam entre vários bilhões e mais de 1 trilhão. Isso alterará radicalmente a maneira que gerenciamos as cadeias de fornecimento, pois permitirá que monitoremos e otimizemos os ativos e as atividades de forma bastante granular. Durante esse processo, todos os setores - desde a fabricação e infraestrutura até o de saúde - receberão impactos transformadores.

A tecnologia da automação representa o surgimento de máquinas automatizadas que possuem vida e inteligência artificiais, capazes de executar digitalmente algoritmos computacionais com vistas a cumprir uma tarefa a serviço do ser humano.

Em um contexto industrial, pode-se definir automação como a tecnologia que dispõe da utilização de sistemas mecânicos, eletroeletrônicos e computacionais na operação e controle de processos. Hoje diversos exemplos de automação podem ser encontrados nas linhas de produção industriais, tais como: máquinas de montagem mecanizadas, sistemas de controle de produção industrial com realimentação e robôs de uso industrial (SILVA; NASCIMENTO, 2003, p. 1).

Podemos ilustrar o fenômeno em questão por meio de um exemplo emblemático: a atual tecnologia conhecida como machine learning (do inglês: aprendizado de máquina), que cada vez mais aprimorada, 
materializa a capacidade de aprender em robôs dotados de inteligência artificial, resultado do esforço de reproduzir as características humanas às máquinas. Entram em cena sistemas lógicos que, a partir dos algoritmos, operam de maneira automatizada por meio dos softwares de inteligência artificial, com impacto profundo no movimento de acumulação global do capital, isto é, máquinas aprendendo com outras máquinas, desde a esfera produtiva até o mercado financeiro - a exemplo dos chamados robôs investidores ${ }^{6}$.

Neste contexto, denominamos como era digital o momento histórico no qual progressivamente todo e qualquer processo estabelecido entre, de um lado, o conteúdo das relações sociais produzido no e pelo trabalho, e de outro, as formas deste conteúdo ser vivenciado pelos indivíduos na experiência da vida em sociedade, pode ser digitalmente automatizado, desde o chão de fábrica até o escritório ou a sala de estar. Por sua vez, em termos técnicos, a digitalização é o processo por meio do qual um dado ou sinal analógico é transformado em código digital ${ }^{7}$.

Segundo o especialista Thomas Cormen (2014, p. 1), autor de Desmitificando algoritmos, um algoritmo é "um conjunto de etapas para executar uma tarefa". De modo geral, todo indivíduo executa algoritmos em sua vida diária na repetição das mesmas etapas, seja para escovar os dentes, preparar o almoço, praticar exercícios físicos ou percorrer o caminho até o trabalho. Cormen ressalta que "Exatamente como os algoritmos que você executa, os algoritmos executados por computadores também afetam a sua vida diária" (CORMEN, 2014, p. 1).

De acordo com José Roberto Piqueira (2016, p. 342), "de maneira simplificada, um algoritmo é uma sequência de operações lógicas e aritméticas, com a finalidade de dar a resposta a um problema passível de ser colocado em linguagem matemática". Neste contexto, a partir das contribuições geniais de nomes como Alan Turing (Criador da Máquina de Turing) e Claude Shannon (Idealizador da Álgebra de Boole e da Teoria Matemática da Comunicação), foi que se tornou possível a chamada arquitetura computacional, proposta por John Von Neumman em 1945, e que permitiu a construção do computador programável - fator tecnológico sem o qual não existiriam, por exemplo, laptops, smartphones ou tablets (PIQUEIRA, 2016, p. 342). Neste contexto, "Chega-se, então, ao conceito de complexidade computacional, entendido como o número de operações necessárias para a execução de um programa, isto é, para a execução de um conjunto de algoritmos" (PIQUEIRA, 2016, p. 342). Na Indústria 4.0, todo esse processo passa a envolver e determinar o processo produtivo em termos globais, seja no chão de fábrica ou no recente fenômeno da uberização

Sob a perspectiva da totalidade do circuito de autovalorização e substantivação do capital na forma de valor (Wertform) - que Marx chamou de processo de produção global -, significa dizer que, na Indústria 4.0, progressivamente, toda a cadeia de produção e reprodução do valor está sendo automatizada digitalmente, desde o trabalho socialmente combinado na esfera da produção - conforme aprofundaremos mais à frente na discussão do conceito de trabalhador coletivo (Gesamtarbeiter) - até o capital financeiro em seu estágio de acumulação fictícia, analisado por Marx no livro terceiro d'O Capital.

$\mathrm{Na}$ era digital, a gestão algorítmica se manifesta como a mão invisivel do trabalho morto que a tudo e a todos administra como uma força autônoma. Os algoritmos estão em toda parte, sabemos que para além da esfera produtiva propriamente dita, eles traçam a melhor rota para se chegar ao trabalho, fazem o clipping das notícias que serão lidas ao longo do dia, realizam a contagem de votos em períodos eleitorais, sugerem as mercadorias a serem consumidas, assim como também controlam a produção, a distribuição, o comércio e as decisões do mercado financeiro (vide nota de rodapé número 6). Neste sentido, o processo de trabalho ganha uma nova materialidade no algoritmo digital. Isto ocorre à medida que cada vez mais se automatiza o processo tecnológico capaz de imitar e materializar eletronicamente os processos subjetivo e objetivo que coordenam a atividade humana em seu caráter produtivo.

Se, por um lado, a inteligência artificial se refere a "mentes" artificiais, a robótica, por sua vez, relaciona-se a "corpos" artificiais. Ambas, IA e robótica, são interdisciplinares, complexas, e se sobrepõem da mesma forma que acontece entre a mente e o corpo humanos, hardware e software. [...] A palavra "robô" foi introduzida pelo escritor checo Karel Capek em 1921, na sua peça R.U.R (Rossum's Universal Robots). O termo deriva de "robota" em checo, que significa trabalho, e é a denominação que o autor dá a seres artificiais criados em fábricas para servir os humanos. De lá pra cá, robôs passaram a significar qualquer entidade - física ou virtual - que possua vida artificial, independentemente do seu nível de inteligência. No entanto, no sentido estrito da palavra, o termo "robô" é mais utilizado para corpos físicos totalmente 
artificiais e existem outras categorias mais específicas para cada tipo de robô, em função da sua aparência (GABRIEL, 2018, p. 215-216).

$\mathrm{Na}$ quarta revolução industrial, a inteligência artificial $^{9}$ e os algoritmos computacionais cercam e preenchem os indivíduos por todos os lados, impulsionados pelo crescimento exponencial da capacidade e da velocidade de processamento das tecnologias da informação e da comunicação (TIC), juntamente com a disponibilidade contínua e sem limites espaciais de uma grande quantidade de dados - leia-se: Big Data ${ }^{10}$. Este processo envolve desde aplicativos usados para descobrir novos medicamentos, até algoritmos que atuam na indústria, avaliam crédito pessoal, prestam assistência jurídica em grandes escritórios de advocacia, tomam decisões no mercado financeiro, ou simplesmente preveem interesses culturais e de consumo. De acordo com Schwab (2016, p. 143),

A Robótica está começando a influenciar muitos postos de trabalho, desde a produção até a agricultura e serviços do varejo. De acordo com a Federação Internacional de Robótica, o mundo agora inclui 1,1 milhão de robôs em funcionamento e as máquinas dão conta de $80 \%$ do trabalho na fabricação de um carro. Os robôs estão agilizando as cadeias de fornecimento para entregar resultados comerciais mais eficientes e previsíveis.

Segundo Feldmann (2018), na Alemanha, robôs já entregam a pizza de domingo; e também a empresa Zume Pizza, do Vale do Silício (Califórnia), entrega comida completamente feita por robôs. Por sua vez, automóveis que dispensam completamente a ação humana já são uma realidade, desde que a Google em 2010 colocou nas ruas o seu primeiro carro autônomo.

\section{Trabalhador coletivo e desenvolvimento tecnológico: a ascensão dos robôs}

No capítulo 14 d'O Capital [Mais-valor absoluto e relativo] (2013, p. 577-586), para analisar a produção capitalista industrializada, Marx apresenta o conceito do chamado Trabalhador coletivo (Gesamtarbeiter). Neste ponto, a primeira questão destacada por ele é que, no modo de produção capitalista, o conceito de trabalho produtivo ${ }^{11}$ sofre uma ampliação de caráter social, vejamos:

\footnotetext{
Enquanto o processo de trabalho é puramente individual, o mesmo trabalhador exerce todas as funções que mais tarde se apartam umas das outras. Em seu ato individual de apropriação de objetos da natureza para suas finalidades vitais, ele controla a si mesmo. Mais tarde, ele é que será controlado. [...] Assim como no sistema natural a cabeça e as mãos estão interligadas, também o processo de trabalho conecta o trabalho intelectual ao trabalho manual. Mais tarde, eles se separam até formar um antagonismo hostil. $\mathrm{O}$ produto, que antes era o produto direto do produtor individual, transforma-se num produto social, no produto comum de um trabalhador coletivo (Gesamtarbeiter), isto é, de um pessoal combinado de trabalho [...]. Desse modo, a ampliação do caráter cooperativo do próprio processo de trabalho é necessariamente acompanhada da ampliação do conceito de trabalho produtivo e de seu portador, o trabalhador produtivo. Para trabalhar produtivamente, já não é mais necessário fazê-lo com suas próprias mãos; basta, agora, ser um órgão do trabalhador coletivo, executar qualquer uma de suas subfunções (MARX, 2013, p. 577-578, grifo nosso).
}

Marx aqui analisa como essa ampliação que faz surgir o trabalhador coletivo, acontece em face do desenvolvimento social e tecnológico do processo de trabalho que, no modo de produção capitalista desenvolvido sob as determinações da indústria, passa a compor um complexo trabalhador socialmente combinado. Atualizando a mediação para a era digital, podemos dizer, por exemplo, que o cérebro (trabalho intelectual) deste trabalhador coletivo pode estar no Brasil, enquanto as suas mãos (operários) podem trabalhar na China de modo eletronicamente conectado, embora humanamente separados - o que analisaremos melhor mais à frente. No entanto, há outro aspecto a examinar: Marx também destaca que não se trata apenas do caráter social de ampliação do trabalho produtivo. É preciso levar em conta um segundo movimento no sentido de alcançar o corolário da contradição em questão, na qual a ampliação, sem ser eliminada, se afirma pela sua própria negação à medida que envolve também um estreitamento do caráter produtivo do trabalho totalizado 
no trabalhador coletivo - prossigamos na leitura da passagem supracitada, na qual Marx explica que, se por um lado, o conceito de trabalho produtivo se amplia,

Por outro lado, o conceito de trabalho produtivo se estreita. A produção capitalista não é apenas produção de mercadoria, mas essencialmente produção de mais-valor. O trabalhador produz, não para si, mas para o capital. Não basta, por isso, que ele produza em geral. Ele tem de produzir mais-valor (Mehrwert). Só é produtivo o trabalhador que produz mais-valor para o capitalista ou serve à autovalorização do capital. (MARX, 2013, p. 577-578; 2016, p. 598, grifo nosso).

Vemos como na sociedade capitalista, a forma social (o valor) que subjuga o caráter produtivo do processo de trabalho ao capital passa a determinar toda a esfera produtiva em termos globais. Afinal, para o capital, o que importa é produzir mais-valor, e isto passa a determinar não somente a situação do trabalho produtivo, mas sobretudo a condição infeliz do trabalhador produtivo, conforme observa Marx (2013, p. 577-578; 2016, p. 598) ao ressaltar neste mesmo trecho que "Ser trabalhador produtivo não é, portanto, uma sorte, mas um azar.". Em suma, o conceito de trabalho produtivo se amplia em seu caráter social de trabalho combinado, ao mesmo tempo que, de maneira intermutável, se restringe à produção de mais-valor. Desse modo, a contradição entre capital e trabalho pulsa como nos movimentos de expansão (diástole) e contração (sístole) do coração humano no ritmo cardíaco que bombeia o sangue no corpo humano; afinal, o mais-valor é o sangue que circula e garante a vida desse corpo social denominado capitalismo.

À medida que se desenvolve a sociedade capitalista, a forma de valor (Wertform) passa a subjugar cada vez mais o processo de trabalho por meio de dois movimentos nevrálgicos que constituem o trabalhador coletivo sob o ponto de vista do valor, e dos quais o segundo é o mais importante para a nossa análise neste momento: i) A produção do mais-valor absoluto, ou a extensão da jornada de trabalho; ii) A produção do mais-valor relativo, que consiste no aumento do grau de produtividade do trabalho sob o fator tecnológico, isto é, quando se produz mais valor em menos tempo (horas trabalhadas) e também com muito menos trabalhadores. A questão é que, se o movimento do mais-valor absoluto encontra historicamente limites na legislação trabalhista oriunda das lutas dos trabalhadores, a exemplo das lutas pela diminuição da jornada de trabalho; o do mais-valor relativo desconhece limites por significar a incorporação dos resultados do desenvolvimento tecnológico ao processo produtivo capitalista.

É a forma social de toda combinação do trabalho o fator característico geral do desenvolvimento da produção capitalista; característica que abrevia o tempo necessário para a produção de mercadorias, ao mesmo tempo em que diminui a massa de trabalhadores [...] para um quantum determinado de mercadorias produzidas. Mas é apenas na maquinaria, e no emprego do novo sistema de máquinas sobre o qual se funda a mecanização das oficinas, que a substituição do trabalhador por uma parte do capital constante (aquela parte do produto do trabalho que se torna novamente meio de trabalho) se coloca, produzindo genericamente um excedente de trabalhadores como tendência expressa e apreensível, que atua e se estabelece em larga escala. O trabalho passado surge aqui como meio para substituir o trabalho vivo ou como aquele meio de fazer diminuir o número de trabalhadores. Esta diminuição do trabalho humano aparece como especulação capitalista, como meio para aumentar a mais-valia (MARX, 1994, p. 103, grifos do autor).

Na Indústria 4.0, a nova denominação para o trabalhador coletivo a partir da arquitetura indivíduomáquina se chama Distributed Control System (DCS) ou Sistema Digital de Controle Distribuído (SDCD). Neste caso, a automação do caráter social do trabalho combinado acontece por meio de sensores dos mais diversos tipos, unidades remotas, entradas e saídas analógicas e digitais controladas por algoritmos computacionais. A partir da inteligência artificial, todo este processo adquire uma interface cada vez mais autônoma, por meio de redes capazes de interconectar robôs de chão de fábrica e processos de nível gerencial, através de estações de controle avançado para a otimização da produtividade (PROSYS, 2016).

Não é novidade que na produção capitalista, a tecnologia se torna fator determinante para subjugar e reduzir o trabalho vivo a um momento do desenvolvimento do capital (trabalho morto), que cada vez mais se comporta como uma força autônoma. Neste contexto, sabemos que antes mesmo da Indústria 4.0 já eram utilizados robôs para executar tarefas mecânicas em vários setores da produção. Para captarmos a atualização dessa questão na era digital, vejamos como fica a situação do trabalhador coletivo nos estágios que formam 
o processo hodierno de produção dos circuitos integrados denominados de chips eletrônicos, uma tecnologia fundamental para a Indústria 4.0, por se constituir a produção do cérebro dos computadores, que ironicamente serve justamente como um substituto artificial do cérebro humano nos mais avançados níveis técnicos do processo produtivo.

Vasconcelos (2018, p. 73) mostra em uma matéria sobre microeletrônica que a cadeia produtiva de chips neste século XXI se divide entre trabalho intelectual e manual constituindo três etapas que envolvem diversas especialidades em uma complexa divisão do trabalho, que pode ser assim resumida: i) Projeto (trabalho intelectual): o desenho e a concepção do esquema elétrico do chip são feitos pelas design house ${ }^{12}$; ii) Fabricação: a produção em larga escala de circuitos integrados em discos de silício, chamados metaforicamente de wafers, fica a cargo das foundries (fábricas que produzem peças fundidas de metal para a indústria microeletrônica, a exemplo dos semicondutores); iii) Montagem: a etapa final acontece em empresas de packaging (leia-se: encapsulamento e teste). Em resumo, tamanho é o caráter social de ampliação do trabalho produtivo neste século XXI, que uma empresa como a gigante Apple Inc. (fabricante do Iphone, Ipad, etc.), pode ter seus engenheiros projetando no Vale do Silício (Califórnia, EUA), enquanto desloca, de maneira conectada, sua produção fabril (fabricação e montagem) para um país asiático com melhores custos de mão de obra. Portanto, a ampliação em rede do caráter produtivo inerente ao trabalhador coletivo na era digital ocorre com velocidade e abrangência jamais concebidas no ultrapassado mundo linear e analógico. Entretanto, para o arremate final da nossa problematização, é preciso examinar pelo menos mais dois aspectos da questão.

Primeiramente, cabe lembrar que a consequência mais imediata derivada da ampliação do caráter social do processo de trabalho no trabalhador coletivo, conforme formulada por Marx, de modo algum, é privilégio da era digital, embora esta traga novos contornos à questão. Como vimos, segundo ele, se antes o trabalhador individual tinha o domínio e o controle do processo de trabalho, na sociedade capitalista desenvolvida, o trabalhador passa a ser dominado e controlado pelo processo produtivo em sua totalidade socialmente desenvolvida, e o desenvolvimento tecnológico exerce uma determinação fundamental neste processo.

No entanto, na era digital, surge a seguinte contradição estabelecida entre trabalho vivo e trabalho morto: a digitalização algorítmica automatiza toda a cadeia produtiva por meio de tecnologias que, se por um lado, reforçam a separação física entre o trabalho intelectual e o manual enquanto sujeitos do trabalho vivo, por outro, integram e conectam eletronicamente cérebros e mãos artificiais na forma do trabalho morto. Em outras palavras, enquanto cérebros e mãos humanas são separados de maneira hostil ${ }^{13}$, em termos artificiais se estabelece ampla conexão, por meio dos robôs globalmente conectados envolvendo todas as etapas (subjetivas e objetivas) da produção a partir do processo de trabalho, assim como também todo o ciclo econômico derivado deste, desde a logística até a distribuição, o consumo e a financeirização. Deste modo, o trabalho morto "ganha vida" e unidade nas máquinas automatizadas digitalmente conectadas em redes, e assim, como um sujeito autônomo subjuga o trabalho vivo fragmentado em escala global; ou seja, a contradição se expressa no fato de que o trabalho é separado e fragmentado como sujeito (trabalho vivo), ao mesmo tempo que se torna altamente conectado como uma força autônoma na sua expressão reificada na e pela automatização digital e algorítmica (trabalho morto).

Em segundo lugar, na era digital, a digitalização algorítmica representa a ampliação da dominação capitalista em todo o espectro imanente à cadeia produtiva, sobretudo em uma dimensão antes intocada: a subjetividade, mais especificamente a dimensão da prévia ideação do objeto a ser produzido. Neste aspecto, o algoritmo digital representa o salto por meio do qual a automação alcança aquela dimensão imanente ao processo de trabalho no que diz respeito ao intelecto e à própria subjetividade. Segundo Costa e Stefano (2014), na produção de automóveis e aeronaves já são realizados testes virtuais das peças, nos quais, um ano antes do início da produção material, o processo previamente idealizado do que será feito no chão de fábrica é experimentado em formato virtual 3D, a exemplo da linha de montagem do Jato Legacy, da Embraer, na qual o tempo de montagem caiu 25\%. Também em montadoras como a Toyota, Fiat e Nissan, "o tempo de desenvolvimento de um novo modelo caiu até $50 \%$ a partir do momento que designers e engenheiros passaram a usar informações digitalizadas e testes virtuais de peças" (COSTA, STEFANO; 2014, p. 1).

Nos Grundrisse, guardadas as devidas proporções do seu tempo, Marx (2011) nos fornece elementos imprescindíveis para analisar a questão em tela, sob um duplo ponto de vista que costura a mediação entre trabalho, tecnologia e valor, isto é: de um lado, o processo (trabalho), e de outro, o resultado (valor/mercadoria/capital). Nesta direção, ele foi certeiro ao perceber que o desenvolvimento tecnológico representa o aprofundamento 
da subsunção do trabalho vivo ao capital, sobretudo no que diz respeito à lógica autoexpansiva da forma de valor (Wertform).

A apropriação do trabalho vivo pelo capital também adquire na maquinaria uma realidade imediata: por um lado, é a análise originada diretamente da ciência e a aplicação de leis mecânicas e químicas que possibilitam à máquina executar o mesmo trabalho anteriormente executado pelo trabalhador. Contudo, o desenvolvimento da maquinaria por essa via só ocorre quando a grande indústria já atingiu um estágio mais elevado e o conjunto das ciências já se encontra cativo a serviço do capital; por outro lado, a própria maquinaria existente já proporciona elevados recursos. [...] Por conseguinte, um modo de trabalho determinado aparece aqui diretamente transposto do trabalhador para o capital na forma de máquina, e por meio dessa transposição sua própria capacidade de trabalho é desvalorizada. Daí a luta dos trabalhadores contra a máquina. Assim, a apropriação do trabalho pelo capital, o capital absorvendo em si o trabalho vivo, se apresenta ante o trabalhador de maneira cruamente perceptível [...]. A troca de trabalho vivo por trabalho objetivado, i. e., o pôr do trabalho social na forma de oposição entre capital e trabalho assalariado, é o último desenvolvimento da relação de valor e da produção baseada no valor (MARX, 2011, p. 587, grifo nosso).

Como fica a relação entre trabalho, tecnologia e valor? Vejamos: do ponto de vista do processo, Marx chama atenção para o fato de que, num primeiro momento, a subsunção do trabalho ao capital adquire na tecnologia uma realidade imediata e hostil para o trabalhador, o que se desdobrou em fenômenos como o ludismo. Por outro lado, sob a perspectiva do resultado (valor), ele também ressalta como a entrada da máquina na esfera produtiva se põe como "o último desenvolvimento da relação de valor e da produção baseada no valor" (MARX, 2011, p. 587).

Neste século XXI, os dados corroboram a validade da análise marxiana. Em 2013, a venda de robôs industriais no mundo bateu recorde: 179 mil unidades (COSTA; STEFANO, 2014). Nesta corrida, o Brasil é retardatário por conta do alto custo da robotização, o que explica porque, segundo dados de 2018, levantados pela Confederação Nacional da Indústria, apenas 1,5\% das empresas brasileiras estão $100 \%$ preparadas para serem totalmente automatizadas. A projeção é de que daqui a dez anos este percentual suba para $25 \%$ (EVANGELISTA, 2018). Ainda assim, somente no Brasil, 15,7 milhões de trabalhadores serão afetados pela automação até 2030, conforme estimativa da consultoria McKinsey (MANYIKA et al 2017).

Martin Ford, em seu estudo Rise of Robots: technology and the threat of a jobless future, nos alerta para uma questão claramente relacionada com o avanço do movimento do mais-valor relativo na era digital: se inicialmente os robôs passaram a integrar o chão de fábrica propriamente dito para realizar tarefas pontuais, agora já encontramos situações nas quais os robôs predominam, de maneira que as pessoas ocupam apenas aquelas vagas que, "Muitas vezes, são trabalhos que envolvem o preenchimento das lacunas entre as máquinas ou estão nos pontos finais do processo de produção." (FORD, 2015, p. 3, tradução nossa).

Uma pesquisa da Oxford Martin School (2016 apud SCHWAB, 2016), realizada em 2010, constatou que até $47 \%$ dos empregos nos Estados Unidos são altamente suscetíveis a serem computadorizados por inteligência artificial (IA) e por robôs nos próximos 20 anos. A realidade é que em todos os setores a diminuição da quantidade de horas de trabalho necessárias para a crescente produção de riqueza ao longo dos últimos anos é alarmante. Mais uma vez, Martin Ford reforça essa realidade no balanço que faz na conclusão da obra supramencionada:

No mesmo mês em que o número total de empregos nos Estados Unidos finalmente retornou aos níveis anteriores à crise, o governo dos EUA divulgou dois relatórios que oferecem alguma perspectiva sobre a magnitude e a complexidade dos desafios que provavelmente enfrentaremos nas próximas décadas. A primeira, que ficou quase completamente anônima, foi uma breve análise publicada pelo Bureau of Labor Statistics (Birô de Estatísticas do Trabalho, sigla em inglês: BLS). O relatório analisou como a quantidade total de trabalho realizado no setor privado dos EUA havia mudado ao longo de quinze anos. Em vez de simplesmente contar os empregos, o BLS investigou o número real de horas trabalhadas. Em 1998, os trabalhadores do setor empresarial dos EUA investiram um total de 194 bilhões de horas de trabalho. Uma década e meia depois, em 2013, o valor dos bens e serviços produzidos pelas empresas americanas cresceu cerca de US\$ 3,5 trilhões [...] (FORD, 2015, p. 281, tradução nossa). 
Ou seja, em menos de duas décadas (entre 1998 e 2013), o valor dos bens e serviços produzidos pelas empresas americanas cresceu cerca de US\$ 3,5 trilhões; um aumento de $42 \%$ na produção, incluindo o ajuste da inflação. No entanto, em termos globais, a quantidade total de trabalho humano necessário para conseguir isso se manteve a mesma (194 bilhões de horas). Conforme analisa Shawn Sprague (SPRAGUE apud FORD, 2015, p. 281), economista do BLS, que preparou o relatório supracitado, "isso significa que não houve crescimento algum no número de horas trabalhadas neste período de 15 anos, apesar do fato de a população dos EUA ter ganhado mais de 40 milhões de pessoas durante esse período de tempo, e apesar do fato de que houve milhares de novas empresas estabelecidas durante esse período". Marx estava certo.

\section{Considerações finais}

Neste século XXI, guardadas as devidas proporções, as concepções gerais elaboradas por Marx ainda no século XIX continuam válidas. No entanto, o aumento do grau de produtividade do trabalho ocorre não somente dispensando progressivamente a força de trabalho humana, mas também significa o crescente controle automatizado do trabalho morto sobre o trabalho vivo. Na Indústria 4.0, a subsunção do trabalho produtivo ao mais-valor se mostra como uma força irreversível e apresenta uma nova materialidade, na qual o trabalho morto "ganha vida" em bits e algoritmos digitais que progressivamente substituem o trabalho vivo por meio da robótica associada com a inteligência artificial.

Uma coisa é certa: a partir das concepções gerais formuladas por Marx acerca do trabalho produtivo e sua relação com a tecnologia, podemos afirmar que a relação entre capital e trabalho na era digital repõe a lei geral da acumulação capitalista sob novos patamares a partir da viragem tecnológica da Indústria 4.0. Na era digital, de maneira mais sofisticada, o trabalhador segue produzindo o seu próprio descarte sob a consolidação da subsunção do trabalho ao capital como um fator tecnológico.

\section{Referências}

AMARAL, F. Introdução à ciência de dados: mineração de dados e Big Data. Rio de Janeiro: Alta books, 2016 (edição digital). ANTUNES, R. Uberização, trabalho digital e Indústria 4.0. São Paulo: Boitempo, 2020.

ARAÚJO, W. P. A ideologia na era digital. Revista Ethic@, Florianópolis, v. 20, n. 2, 461-488, Ago. 2021. Disponível em: https:// periodicos.ufsc.br/index.php/ethic/article/view/82589/47563 Acesso em 08. dez. 2021.

CORMEN, T. H. Desmistificando Algoritmos. Rio de Janeiro: Elsevier, 2014.

COSTA, M.; STEFANO, F. A era das fábricas inteligentes está começando. Revista Exame, São Paulo, ago. 2014. Disponível em: https://exame.abril.com.br/revista-exame/a-fabrica-do-futuro/. Acesso em 09. abril. 2019.

EVANGELISTA, A. P. Seremos livres ou escravos da Indústria 4.0?. Rio de Janeiro: EPSJV/Fiocruz, 2018. Disponível em: https:// www.epsjv.fiocruz.br/noticias/reportagem/seremos-lideres-ou-escravos-da-industria-40. Acesso em 29. jun. 2021.

FEDERICI, S. O ponto zero da revolução. São Paulo: Elefante, 2019.

FELDMANN, P. Era dos robôs está chegando e vai eliminar milhões de empregos. Jornal da Universidade de São Paulo, São Paulo, 3 ago. de 2018. Disponível em: https://jornal.usp.br/artigos/era-dos-robos-esta-chegando-e-vai-eliminar-milhoes-de-empregos/. Acesso 7 ago. 2018.

FORD, M. Rise of the robots: technology and the threat of a jobless future. New York: Basic Books, 2015.

GABRIEL, M. Você, eu e os robôs: pequeno manual do mundo digital. São Paulo: Atlas, 2018.

MANYIKA, J. et al. O futuro do mercado de trabalho: impacto em empregos, habilidades e salários. McKinsey \& Company, [s.l.], nov. 2017. Disponível em: https://www.mckinsey.com/featured-insights/future-of-work/jobs-lost-jobs-gained-what-the-future-of-workwill-mean-for-jobs-skills-and-wages/pt-br. Acesso em: 27. junho. 2021.

MARX, K. Maquinaria e trabalho vivo (os efeitos da mecanização sobre o trabalhador). Crítica Marxista, São Paulo, v. 1, n. 1, ano 1994, p. 103-110.

MARX, K. Das Kapital - Kritik der politischen Ökonomie. Der Produktionsprozess des Kapitals. Hamburg: Nikol Verlag, 2016.

MARX, K. Grundrisse: manuscritos econômicos de 1857-1858: esboços da crítica da economia política. São Paulo: Boitempo, 2011.

MARX, K. O Capital - Crítica da Economia Política. Livro 1 - O processo de produção do capital. São Paulo: Boitempo, 2013.

PIQUEIRA, J. R. C. Complexidade computacional e medida da informação: caminhos de Turing e Shannon. Revista Estudos Avançados, São Paulo, v. 30, n. 87, 2016. 
PROSYS. Engenharia. Afinal, que é DCS e SDCD?. Barueri, 2016. Disponível em: http://www.prosyseng.com.br/439/afinal-o-quee-dcs-e-sdcd/\#.YNuWuetv9QJ. Acesso em 29 jun. 2021.

SCHWAB, K. A Quarta Revolução Industrial. São Paulo: Edipro, 2016.

SILVA, D. S. da; NASCIMENTO, J. M. A. do. Automação Industrial. Departamento de Engenharia de Computação e Automação, Rio Grande de Norte, maio 2003, Disponível em: https://www.dca.ufrn.br/ affonso/FTP/DCA447/trabalho1/trabalho1_4.pdf. Acesso em 13 out. 2018.

VASCONCELOS, Y. O sonho do chip. Nova fábrica de circuitos integrados da Qualcomm poderá colocar o Brasil no time dos produtores globais de semicondutores. Revista Pesquisa, FAPESP, São Paulo, n. 266, p. 70-81, abr. 2018. Disponível em: https://revistapesquisa. fapesp.br/folheie-a-edicao-266/. Acesso em: 7 set. 2021.

ZORZECCO, R. Em estágio final de construção, fonte de luz sincrotron de última geração pode elevar a qualidade da pesquisa brasileira. Revista Pesquisa, FAPESP, São Paulo, n. 269, ano 2018, p. 18. Disponível em: https://revistapesquisa.fapesp.br/folheie-aedicao-269/. Acesso em: 7 set. 2021.

ZUBOFF, S. A era do capitalismo da vigilância: a luta por um futuro humano na nova fronteira de poder. Rio de Janeiro: Intrínseca, 2021 (edição digital).

\section{Notas}

1 O termo Indústria 4.0 foi cunhado em 2011 na feira de Hannover para descrever como a quarta revolução industrial irá transformar a organização das cadeias globais do valor (SCHWAB, 2016, p. 16).

2 Segundo Jesus Ranieri, “Os Manuscritos de 1861-63 (compostos por 23 cadernos) representam o momento de passagem entre os Grundrisse e $O$ Capital, sendo parte importante do material preparatório deste último. O presente extrato encontra-se no interior da sequência denominada A mais-valia relativa - acumulação, referente ao caderno XX, redigido entre março e maio de 1863 " (RANIERI, 1994 apud MARX, 1994, p. 103).

3 Quando, nas citações d'O Capital, aparecem duas referências no tocante ao ano (AUTOR, DATA; DATA), significa que, para maior aprofundamento da argumentação conceitual, mesclamos a tradução em português com extratos do texto original, trazidos entre parênteses no interior da própria citação.

4 Também temos um caso particular de trabalho vivo, ignorado nos Grundrisse, que diz respeito às atividades reprodutivas no campo do trabalho doméstico (não remunerado), conforme problematiza Silvia Federici (2019) - que não é caso de abordar neste momento.

5 No caso específico da nossa argumentação, é possível interpretar trabalho morto e trabalho passado como sinônimos. No entanto, é preciso guardar a seguinte ressalva: o sentido de trabalho morto apresentado em $O$ Capital - a exemplo da nossa epígrafe - é mais amplo do que aquele situado na concepção de trabalho passado encontrada no manuscrito Maquinaria e trabalho vivo (MARX, 1994). Enquanto o primeiro ilustra o caráter parasitário do capital em sua generalidade, que pode eventualmente ser aplicado ao trabalho passado, este último diz respeito especificamente à relação entre trabalho vivo e maquinaria sob o desenvolvimento tecnológico. Portanto, no sentido da análise da relação específica entre maquinaria e trabalho vivo, todo trabalho passado é trabalho morto, porém, em termos mais amplos, nem todo trabalho morto é trabalho passado, justamente por este último se referir exclusivamente ao fator tecnológico.

6 Segundo Zorzecco (2018, p. 18) “Os algoritmos estão em toda parte. Quando a bolsa sobe ou desce, eles geralmente estão envolvidos. Segundo dados divulgados em 2016 pelo Instituto de Pesquisa Econômica Aplicada (IPEA), robôs investidores programados para reagir instantaneamente a determinadas situações são responsáveis por $40 \%$ das decisões de compra e venda no mercado de ações no Brasil - nos Estados Unidos, o percentual chegou a 70\%."

7 De acordo com Amaral (2016, p. 19-20), “Dados são fatos coletados e normalmente armazenados. Informação é o dado analisado e com algum significado. O conhecimento é a informação interpretada, entendida e aplicada para um fim. [...] O dado pode estar em formato eletrônico analógico ou digital. Ele ainda pode existir em um formato não eletrônico. O dado não eletrônico é aquele que normalmente está impresso em papel, mas poderia estar até em uma pedra esculpida por um homem de Neandertal. [...] O dado analógico é transmitido por ondas e pode sofrer interferência eletromagnética. Já o dado digital é transmitido em pacotes de bits, mais eficientes e sofrendo menos interferências".

8 Pelos próprios limites e possibilidades desta exposição, não será o caso de desenvolver a questão específica do fenômeno da uberização (Cf. ANTUNES, 2020).

9 Segundo Gabriel (2018, p. 216), "quanto à aparência, as inteligências artificiais podem ser robôs, bots, androids e cyborgs (híbridos)." - para maiores detalhes, cf. Gabriel, 2018, p. 215-225. 
10 Segundo Amaral (2016, p. 24), "Big Data é o fenômeno em que dados são produzidos em vários formatos e armazenados por uma grande quantidade de dispositivos e equipamentos". Ademais, cabe ressaltar que diante dos limites desta exposição, não aprofundaremos aqui a questão do Big Data - para estudos importantes e destacados sobre este tema, Cf. AMARAL, 2016; ARAÚJO, 2021; ZUBOFF, 2021.

11 Marx (2013, p. 255-275) refere-se ao conceito anteriormente apresentado no início do quinto capítulo da mesma obra [Processo de trabalho e processo valorização], no qual o processo de trabalho ainda aparece como uma formulação geral e válida para todas as épocas, mas ainda insuficiente para a crítica do capitalismo - conforme ele salienta em nota de rodapé: "Essa determinação do trabalho produtivo, tal como ela resulta do ponto de vista do processo simples de trabalho, não é de modo algum suficiente para ser aplicado ao processo capitalista de produção" (MARX, 2013, p. 258). Essa questão se explica no fato de que a conceituação do processo de trabalho em sua universalidade continua válida, mas não é mais suficiente, tendo em vista que é preciso submeter o universal à inferência da particularidade histórica, neste caso, a produção do tipo capitalista.

12 Segundo o portal do Programa Nacional de Formação de Projetistas de Circuitos Integrados (CI Brasil), existem 22 Design Houses distribuídas por todo o território nacional (VASCONCELOS, 2018).

13 Processo que favorece politicamente a dominação capitalista, à medida que fragmenta e inviabiliza a consciência coletiva de classe na formação ideológica dos trabalhadores - obviamente, questão que exige uma outra exposição.

\section{Wécio Pinheiro Araújo}

wecio.araujo@academico.ufpb.br

Doutor em Filosofia pelo Programa Integrado de Doutorado UFPE/UFPB/UFRN, com estágio sanduíche (CAPES/PDSE) na Hochschule für Grafik und Buchkunst (HGB/Leipzig/Alemanha)

Professor Adjunto III na Universidade Federal da Paraíba (UFPB)

Professor permanente do Programa de Pós-graduação em Serviço Social (PPGSS/UFPB) e colaborador no Programa de Pós-graduação em Filosofia (PPGFIL/UFPE)

\section{UFPB}

Departamento de Serviço Social (DSS/CCHLA)

Conjunto Humanístico, Bloco IV, Campus I, Cidade Universitária

Joao Pessoa, PB - Brasil

CEP: 58059-900

\section{Agradecimentos}

Agradeço à CAPES, que me proporcionou a oportunidade de estágio doutoral na Alemanha (PDSE processo $n$. $^{\circ}$ $88881.133482 / 2016-01$ ), período que muito contribuiu para o crescimento da minha pesquisa.

\section{Agência financiadora}

Não se aplica.

Contribuições das autoras

Não se aplica.

\author{
Aprovação por Comitê de Ética e consentimento para \\ participação \\ Não se aplica. \\ Consentimento para publicação \\ Consentimento do autor. \\ Conflito de interesses \\ Não há conflito de interesses.
}

